\title{
Spray Dried, Pasteurised Bovine Colostrum Protects Against Gut Dysfunction and Inflammation in Preterm Pigs
}

Støy, Ann Cathrine Findal; Sangild, Per T.; Skovgaard, Kerstin; Thymann, Thomas; Bjerre, Mette; Chatterton, Dereck E.W.; Purup, Stig; Boye, Mette; Heegaard, Peter M. H.

Published in:

Journal of Pediatric Gastroenterology and Nutrition

Link to article, DOI:

$10.1097 / \mathrm{mpg} .0000000000001056$

Publication date:

2016

Document Version

Peer reviewed version

Link back to DTU Orbit

Citation (APA):

Støy, A. C. F., Sangild, P. T., Skovgaard, K., Thymann, T., Bjerre, M., Chatterton, D. E. W., Purup, S., Boye, M., \& Heegaard, P. M. H. (2016). Spray Dried, Pasteurised Bovine Colostrum Protects Against Gut Dysfunction and Inflammation in Preterm Pigs. Journal of Pediatric Gastroenterology and Nutrition, 63(2), 280-287.

https://doi.org/10.1097/mpg.0000000000001056

\section{General rights}

Copyright and moral rights for the publications made accessible in the public portal are retained by the authors and/or other copyright owners and it is a condition of accessing publications that users recognise and abide by the legal requirements associated with these rights.

- Users may download and print one copy of any publication from the public portal for the purpose of private study or research.

- You may not further distribute the material or use it for any profit-making activity or commercial gain

- You may freely distribute the URL identifying the publication in the public portal 
JPGN Journal of Pediatric Gastroenterology and Nutrition Publish Ahead of Print

DOI : 10.1097/MPG.0000000000001056

Spray dried, pasteurised bovine colostrum protects against gut dysfunction and inflammation in preterm pigs

Ann Cathrine F. Støy $\mathrm{PhD}^{1,2}$, Per T. Sangild PhD, DVSc, DMSc ${ }^{2}$, Kerstin Skovgaard $\mathrm{PhD}^{1}$, Thomas Thymann $\mathrm{PhD}^{2}$, Mette Bjerre $\mathrm{PhD}^{3}$, Dereck E.W. Chatterton $\mathrm{PhD}^{2,4}$, Stig Purup $\mathrm{PhD}^{5}$, Mette Boye $\mathrm{PhD}^{1}$, Peter M. H. Heegaard $\mathrm{PhD}^{1}$

${ }^{1}$ National Veterinary Institute, Technical University of Denmark, Frederiksberg, Denmark;

${ }^{2}$ Comparative Paediatrics and Nutrition, Department of Clinical Veterinary and Animal Science, University of Copenhagen, Frederiksberg, Denmark; ${ }^{3}$ The Medical Research Laboratories, Department of Clinical Medicine, Faculty of Health Sciences, Aarhus University, Aarhus, Denmark; ${ }^{4}$ Department of Food Science, University of Copenhagen, Frederiksberg, Denmark; ${ }^{5}$ Department of Animal Science, Aarhus University, Tjele, Denmark

Corresponding author: Peter M. H. Heegaard, Innate Immunology Group, National Veterinary Institute, Technical University of Denmark, 27 Bülowsvej, DK-1870 Frederiksberg C, Denmark; email: pmhh@vet.dtu.dk; tel. +45 35886241; fax. +45 35886001.

Conflicts of Interest and Source of Funding: This work was supported by the Danish Strategic Research Councils. The study also received support from Biofiber-Damino, Gesten, Denmark which also donated the colostrum for the study. Biofiber-Damino had no role in the design, analysis or writing of this article. University of Copenhagen has filed a patent application regarding the use of bovine colostrum for paediatric patients. Per Sangild is listed as sole inventor but has declined 
any share of potential revenue arising from commercial exploitation of such a patent. All other authors have no conflicts of interest.

Runing title: Beneficial effects of processed colostrum

Figures and tables: 6 figures, 0 tables

Author contribution: PTS and TT designed the study; ACFS, PTS, TT carried out animal study; ACFS, KS, MB, DEWC, SP, and MB carried out laboratory analyses and experiments; ACFS, PTS, KS, MB, DEWC, SP, PMHH analysed data, performed statistical analyses and/or drafted parts of the manuscript; ACFS, PTS, PMHH wrote the paper and had primary responsibility for the final content. All authors reviewed the manuscript.

\section{Abstract}

Objective: Feeding bovine colostrum $(\mathrm{BC})$ improves gut maturation and function, and protects against necrotizing enterocolitis (NEC), relative to formula in newborn preterm pigs. Before $\mathrm{BC}$ can be used for preterm infants, it is important to test if the milk processing, required to reduce bacterial load and increase shelf life, may affect bioactivity and efficacy of a BC product.

Methods: We investigated if spray dried, and pasteurised, spray dried BC had protective effects on gut function in preterm pigs, relative to formula. After a 2-day total parenteral nutrition period, preterm pigs were fed formula for a few hours (to induce a pro-inflammatory state) followed by 2 days of formula (FORM, $\mathrm{n}=14)$, BC $($ COLOS, $\mathrm{n}=14)$, spray dried $\mathrm{BC}(\mathrm{POW}, \mathrm{n}=8)$, or pasteurised, spray dried BC (POWPAS, $n=9)$.

Results: Spray drying and pasteurisation of BC decreased the concentration of TGF- $\beta 1$, TGF- $\beta 2$ and increased protein aggregation. All three BC groups had reduced NEC severity, small intestinal levels of IL-1 $\beta$, IL-8 and colonic lactic acid levels, and increased intestinal villus height, hexose 
absorption, and digestive enzyme activities, relative to the FORM group (all $P<0.05$ ). All three BC diets stimulated epithelial cell migration in a wound-healing model with IEC-6 cells.

Conclusion: Spray drying and pasteurisation affect BC proteins, but do not reduce the trophic and anti-inflammatory effects on the immature intestine. It remains to be studied if BC products will benefit preterm infants just after birth when human milk is often not available.

Keywords: animal model, necrotizing enterocolitis, formula, diet, prematurity

\section{What is known}

- Mother's milk and bovine colostrum have a high level of bioactive factors while formula lacks such factors.

- Bovine colostrum improves gut maturation, function and necrotizing enterocolitis resistance, relative to formula in preterm pigs.

- Processing of milk products is required for use in clinical settings, but this may also reduce their bioactivity.

\section{What is new}

- Pasteurised, spray dried bovine colostrum reduces necrotizing enterocolitis and inflammation and increases gut function, relative to infant formula in preterm pigs.

- Spray drying does not markedly damage colostrum milk proteins, while pasteurisation results in some protein aggregation and reduced concentration of bioactive factors. 


\section{Introduction}

Colostrum is rich in bioactive factors compared with mature milk, which are essential in stimulating gastrointestinal and immunological maturation, and a favourable gut microbiota (1-5). Colostrum may be particularly important for compromised preterm neonates, as their intestinal immaturity may lead to maldigestion, bacterial dyscolonisation and dys-regulated immune responses, which potentially can lead to necrotising enterocolitis (NEC). Feeding bovine colostrum (BC), mature milk or human donor milk improves gut development and NEC protection in preterm pigs, compared with formula (6-8), with minimal NEC symptoms when BC is fed in slowly advancing volumes from birth $(9,10)$. Likewise, preterm infants fed mother's own milk have a reduced risk of NEC, compared with preterm infants fed formula, also when combined with human donor milk (1114). Mother's milk is often absent or limited during the first critical days after birth (14), and in this situation, $\mathrm{BC}$ could be an alternative to formula that lacks important bioactive components. Preliminary studies show that raw and reconstituted BC powder is well-tolerated by children with short bowel syndrome (15) and newborn preterm infants (16), respectively. However, the efficacy of $\mathrm{BC}$ products in response to different milk processing conditions, and relative to formula products, is difficult to assess in infants. Heat treatment, including spray drying and pasteurisation, increases shelf life, reduces bacterial load, and facilitates handling of BC products, but it may also affect its bioactivity due to loss or reduction of bioactive factors. Gentle heat treatment of milk whey protein concentrate has shown to preserve bioactive factors and improve gut development in preterm pigs, although the products based on mature bovine milk remain inferior to $\mathrm{BC}(17)$.

We hypothesised that spray drying and pasteurisation would not markedly affect the beneficial effects of $\mathrm{BC}$ on the immature intestine, compared with formula. This was investigated in a preterm pig model of NEC, investigating intestinal structure and functions, microbiota, and tissue protein and mRNA levels of immune factors. An in vitro cell migration assay was used to determine wound healing in the presence of increasing doses of the three BC products. Finally, the concentration of 
some bioactive proteins and treatment-related aggregation of proteins in the $\mathrm{BC}$ products were determined.

\section{Methods}

\section{Animal procedures}

Forty-five preterm pigs were delivered from four sows (Large White $\times$ Danish Landrace $\times$ Duroc) by caesarean section at $105-107 \mathrm{~d}$ of gestation (90-92\% gestation). The procedures for caesarean section and nursing of the preterm pigs followed a standard protocol (18). Each pig received intraarterial infusions of maternal porcine plasma at 3,8 and $12 \mathrm{~h}$ after birth $(4,5$, and $7 \mathrm{ml} / \mathrm{kg}$ body weight (BW), respectively) to provide passive immunity. The pigs were given total parenteral nutrition (TPN) for $48 \mathrm{~h}$ based on Nutriflex Lipid Plus (Braun, Melsungen, Germany; $4 \mathrm{ml} / \mathrm{kg}$ advancing to $6 \mathrm{ml} / \mathrm{kg}$ per h) adjusted in composition to meet the nutritional requirements of the preterm pigs (18). Hereafter, the pigs were given total enteral nutrition for $2 \mathrm{~d}$ before euthanasia and tissue collection. During the first $6 \mathrm{~h}$ of enteral feeding, all pigs received formula ( $80 \mathrm{~g}$ Pepdite, 70 g Maxipro, and 75 g Liquigen per litre of water (18), kindly donated by Nutricia, Allerød, Denmark). Hereafter, the pigs were allocated according to birth weight into the four enteral nutrition groups (feeding dose, $15 \mathrm{ml} / \mathrm{kg} \mathrm{BW} / 3 \mathrm{~h})$ : $\mathrm{BC}(\mathrm{COLOS}, \mathrm{n}=14)$, reconstituted spray dried $\mathrm{BC}(\mathrm{POW}, \mathrm{n}=8)$, reconstituted, pasteurised and spray dried BC (POWPAS, $n=9)$, or formula (FORM, $n=14$ ). Collectively, pigs fed COLOS, POW or POWPAS are abbreviated BC pigs. The $\mathrm{BC}$ products were produced from the same batch of first milking after parturition and kindly donated by Biofiber-Damino, Gesten, Denmark. Pasteurisation of liquid BC was performed at $72{ }^{\circ} \mathrm{C}$ for $15 \mathrm{~s}$ and spray drying was performed by filter mat spray drying (confidential procedure, Biofiber-Damino). COLOS, POW and POWPAS were sterilised by irradiation ( 1 x $10 \mathrm{kGy}$, Sterigenics, Espergærde, Denmark), to ensure that all BC products were completely free of bacterial activity. This was tested using C-calves blood agar (SSI Diagnostica, Hillerød, Denmark) under anaerobic and aerobic conditions at $37^{\circ} \mathrm{C} / 24 \mathrm{~h}$. The energy and macronutrient content of $\mathrm{BC}$ was 
calculated using reported measurements, and the BC products were diluted in tap water to obtain isoenergetic products $(\sim 4,000 \mathrm{~kJ} / \mathrm{L})(19)$. The products were stored at $-20^{\circ} \mathrm{C}$, and ensured to be homogenous and warmed to body temperature in a water bath before use. All animal procedures were approved by the Danish National Committee on Animal Experimentation (Licence: 2004/561910).

\section{Clinical evaluation, tissue collection and gut morphology}

Pigs were monitored closely and euthanized if clinical symptoms of NEC such as abdominal distension, lethargy, cyanosis or bloody diarrhoea were observed. Pigs not showing clinical signs of NEC were euthanized after $45-50 \mathrm{~h}$ of enteral feeding, and only pigs that had received treatment diets were included in the study. Euthanasia and tissue collection were performed according to earlier described protocols (20). The proximal, middle and distal small intestine, stomach and colon were evaluated for macroscopic lesions and assigned an NEC score from 1-6, where one was assigned to a normal region and six to a severely affected region with pneumatosis intestinalis and extensive haemorrhagic necrosis, as previously described (6). Pigs with a score of $\geq 3$ in any region were regarded as a case of NEC. The mean NEC score was calculated as the mean of the NEC score from the five regions. Samples from the small intestinal regions were immediately snap-frozen and stored at $-80^{\circ} \mathrm{C}$ for immune and enzyme assays. Distal small intestinal samples were prepared for fluorescence in situ hybridisation (FISH) and morphology measurements (villus height and crypt depth), and the proportion of dry mucosa and circumference, of each small intestinal region, were measured as previously described $(6,21)$.

\section{Intestinal digestive capacity, absorption and permeability}

Intestinal digestive capacity was measured in homogenized (see above) intestinal samples as hydrolytic activities expressed as Unit (U)/g of wet intestine of aminopeptidase A, aminopeptidase $\mathrm{N}$, dipeptidyl-peptidase IV, lactase and maltase as previously described (22). Trehalase activity was 
measured as described for lactase and maltase using 0.6 M D-(+)-trehalose dihydrate (SigmaAldrich, Brøndby, Denmark) as a substrate. For all enzymes, $1 \mathrm{U}$ of enzymatic activity was equal to hydrolysis of $1 \mu \mathrm{mol}$ substrate $/ \mathrm{min}$ at $37^{\circ} \mathrm{C}$. To test the intestinal absorption capacity, an oral bolus of $15 \mathrm{ml} / \mathrm{kg} \mathrm{BW}$ of a $5 \%$ galactose solution was given before, $6 \mathrm{~h}$ and $30 \mathrm{~h}$ after enteral food introduction and blood was collected after $20 \mathrm{~min}$ and analysed as previously described (23). For the latter two time points, the bolus was given at least $2.5 \mathrm{~h}$ after the previous feeding. To assess intestinal permeability, an oral bolus of 5\% lactulose and 2\% mannitol (15 ml $/ \mathrm{kg} \mathrm{BW})$ was given 4 to $6 \mathrm{~h}$ prior to euthanasia, at which time, urine was collected and analysed as described previously (18).

Small intestinal and plasma levels of immune genes and proteins

The concentration of IL-1 $\beta$, IL-6, IL-8, and IL-10 in distal small intestinal samples (homogenised in $1 \%$ Triton $\mathrm{X}-100,6 \mathrm{ml} / \mathrm{g}$ wet tissue) or plasma (sampled at euthanasia (6)) was determined using a multiplex bead based assay, with the addition of IL- $1 \beta$ to the assay, and using the same conditions as described for this cytokine (24). The results were expressed relative to the total protein concentration in each sample, which was determined by spectrophotometry (E280). Serum amyloid A (SAA) plasma concentrations were determined using an ELISA kit according to the manufacturer's instructions (Tridelta Developments Ltd. Maynooth, County Kildare, Ireland). The gene expression of $I L 1 B, I L 6, I L 8, T L R 4, T N F, I L 10, D E F B 4 A, S A A$, and reference genes ACTB, $B 2 M$ and HPRT1 in the distal small intestine was determined using reverse transcription real-time quantitative PCR as previously described, where also information on reference genes $(B 2 M, A C T B$, and HPRT1) and genes of interest can be found (6). Gene expression differences were assessed by setting the mean for the COLOS group to one, and the mean of the gene in question from the other groups was displayed as relative expression, compared with the COLOS group. 


\section{Bacterial abundance, location and fermentation products}

FISH was performed on formaldehyde-fixed distal small intestine sections using an AlexFluor555oligonucleotide general bacteria probe (5'-GCTGCCTCCCGTAGGAGT-3', Eurofins MWG Operon AG, Ebersberg, Germany) as previously described $(6,25)$. The most representative crosssection from each pig was evaluated for bacterial abundance (score $1-5$, where one correspond to no or very few microcolonies and 5 to extensive colonisation) and bacterial location (score 1-4, where one was assigned when the bacteria were only in the lumen and 4 , when the bacteria were throughout the section and translocated to muscularis mucosae) as previously described (6). As a marker of bacterial metabolic activity, the concentration of 15 organic acids $(\mathrm{OA})$ in stomach and colon contents was measured as described previously, using one gram of sample in the extraction procedure (26).

\section{Migration of intestinal epithelial cells in vitro}

A scratch wound assay was performed to quantify cell migration as described earlier (27). Rat intestinal epithelial cells (IEC-6, ACC 111, DSMZ, Braunschweig, Germany) were maintained in culture medium consisting of Dulbecco’s Minimal Essential Medium (Invitrogen, Tåstrup, Denmark) supplemented with fetal calf serum (10\%, FBS, Cambrex Bio Science, Copenhagen, Denmark), sodium pyruvate (0.4 mM; Invitrogen), Glutamax (2 mM, Invitrogen), and penicillin/streptomycin solution (1\% (v/v), Sigma-Aldrich, Vallensbæk Strand, Denmark) at $37^{\circ} \mathrm{C}$ and $5 \% \mathrm{CO} 2$. Cells were incubated in 12 -well plates $\left(2 \times 10^{5}\right.$ cells/well $)$ overnight and a standardised cell-free area was made with a pipette tip. Cells were washed carefully with phosphate-buffered saline (Invitrogen) and incubated with $0-10 \%(\mathrm{v} / \mathrm{v})$ whey from COLOS, POW and POWPAS in culture medium without FBS. Whey was prepared from COLOS (1:5 dilution), and POW or POWPAS $(10 \%, \mathrm{v} / \mathrm{v})$ as previously described (28). The migration distance from the original wound border was determined by photomicrographs immediately after wounding and 5-6 h after. 


\section{Characterisation of some growth factors and proteins in BC products}

The concentration of insulin-like growth factor (IGF-I), transforming growth factor (TGF)- $\beta 1$ and TGF- $\beta 2$ was determined in two replicate measurements by time-resolved immune-fluorescence assay (IGF-I) and ELISA (TGF- $\beta 1$, TGF- $\beta 2$ ) in whey fractions of COLOS, POW and POWPAS as previously described (28). BC protein denaturation and aggregation were determined by SDSPAGE analysis. Briefly, $1 \%(\mathrm{w} / \mathrm{v}) \mathrm{BC}$ solutions were prepared and used without further treatment or centrifuged (15 min; 13,000g). Following centrifugation, the supernatants were sampled without disturbing the lipid layer. Samples were heated to $95^{\circ} \mathrm{C}$ for $3 \mathrm{~min}$ in non-reducing Laemmli sample buffer and then $11.25 \mu \mathrm{g}$ of protein from each sample was applied to $12 \%$ Tris/Glycine SDS-PAGE gels and proteins separated using electrophoresis. Proteins were visualised by staining with Coomassie Brilliant Blue. The relative molecular weight of the proteins was determined by comparison to the migration of a molecular weight marker, See Blue (Invitrogen).

\section{Statistical analyses}

In the in vivo study, NEC incidence was analysed using Fisher's exact test, with subsequent pairwise comparisons. All other data were analysed using the parametric analysis of variance, ANOVA, either as the PROC MIXED model of SAS (v9.1, SAS Institute, NC, USA) with treatment and region as fixed variables (mean NEC score and enzyme activities) or treatment as fixed variable, and litter as random variable. Gene expression data were log2 transformed, and for all other data, in cases of non-normality, $\log 10$ transformation was done before analysis. Spearman correlation was performed in GraphPad Prism (v5.02; La Jolla, CA, USA), and the relationship between two variables were considered to correlate when Spearman's rho, $\rho<-0.5 />0.5$, equal to $P<0.001$. Data are presented as mean with standard error of the mean $(\mathrm{SEM})$ and $P<0.05$ was used as the critical level of significance. Furthermore, for gene expression data a fold-change of $\geq 2$ (linear scale) were defined as a cutoff for biological significance. In the in vitro study, the effect of 
COLOS, POW and POWPAS whey on IEC-6 cells migration was analysed using the PROC MIXED procedure of SAS with whey and concentration as fixed variables and number of replicates/treatment $(n=12)$ as random variable. Values are presented as relative migration based on least-squares means $+\mathrm{SEM}$, and $P<0.05$ used as the critical level of significance.

\section{Results}

\section{Clinical outcome, organ and intestinal dimensions}

The mean NEC score was higher in FORM than in POWPAS and POW pigs, and in COLOS compared with POWPAS pigs (Figure 1a), while a near-significant difference was observed between COLOS and FORM pigs $(P=0.06)$. The incidence of NEC was higher in FORM than POWPAS pigs, and with intermediate values in COLOS and POW pigs (Figure 1b). Additionally, FORM pigs had reduced life span compared with POW and POWPAS pigs, with an intermediate value for COLOS pigs (Figure 1c). Distal small intestinal villus height was lower, and the small intestinal circumference was increased in FORM, relative to BC pigs (Figure 1d,e).

No group differences were observed in BW at birth (pooled value, $900 \pm 28 \mathrm{~g}$ ) or at euthanasia (pooled value, $950 \pm 30 \mathrm{~g}$ ), relative length of the small intestine (pooled value, $322 \pm 10 \mathrm{~cm} / \mathrm{kg}$ ), distal small intestinal crypt depth (pooled value, $96 \pm 3 \mu \mathrm{m}$ ), the percentage of small intestinal dry mucosa (pooled values, $69 \pm 1 \%$ ), small intestinal area (pooled value, $291 \pm 8 \mathrm{~cm} 2$ ), or relative weights (pooled values) to $\mathrm{BW}(\mathrm{g} / \mathrm{kg})$ of stomach $(6.7 \pm 0.3)$, small intestine $(30.0 \pm 0.9)$, large intestine $(9.5 \pm 0.4)$, heart $(8.0 \pm 0.2)$, lungs $(21.6 \pm 0.8)$, liver $(26.0 \pm 0.4)$, kidneys $(9.9 \pm 0.3)$ and spleen $(2.0 \pm 0.1)$

\section{Intestinal digestive capacity, absorption and permeability}

Across the small intestinal regions, the activity of five of six enzymes was higher in BC, compared with FORM pigs, while some differences were also observed among the BC pigs (Figure $1 \mathrm{f}-\mathrm{j}$ ). The activity of trehalase was similar between groups (pooled values, $0.32 \pm 0.01 \mathrm{U} / \mathrm{g}$ of wet intestine). 
Galactose absorption did not differ between groups at $0 \mathrm{~h}$ and $6 \mathrm{~h}$, but was higher at $30 \mathrm{~h}$ in $\mathrm{BC}$ than FORM pigs (Figure 2). No treatment effect was observed for the intestinal permeability measured as the ratio of lactulose to mannitol (pooled values, $0.08 \pm 0.02$ ).

Small intestinal and plasma levels of immune genes and proteins The protein concentration of IL-1 $\beta$ and IL- 8 in the distal small intestine was higher in FORM than in BC pigs (Figure 3a,b). Furthermore, IL-1 $\beta$ correlated positively with the distal small intestinal NEC score $(\rho=0.50, P<0.001)$ and with $\operatorname{IL1B}(\rho=0.56, P<0.001)$. In contrast, no significant correlations were found between IL-8 and IL8 or the distal small intestinal NEC score (not shown). Plasma IL-10 (pooled values, $53.0 \pm 5.5 \mathrm{pg} / \mathrm{ml}$ ) and SAA (pooled values, $83 \pm 11 \mu \mathrm{g} / \mathrm{ml}$ ) levels were similar across groups, and did not correlate significantly with the mean NEC score (not shown). The concentrations of IL-6 and IL-10 in the distal small intestine, and plasma levels of IL$1 \beta$, IL-6, and IL-8, were generally below detection limit (data not shown).

In the distal small intestine, a moderately up-regulation of DEFB4A was observed in POWPAS, relative to COLOS pigs $(2.3 \pm 0.5$ versus $1.0 \pm 0.3$, respectively, $P<0.05)$, with intermediate values in FORM $(1.7 \pm 0.6)$ and POW pigs $(2.1 \pm 1.0)$. Also for $S A A$ a moderately up-regulation in POW $(2.8 \pm 1.1)$, compared with COLOS pigs $(1.0 \pm 0.4, P<0.05)$ was observed, with intermediate values for FORM $(1.4 \pm 0.4)$ and POWPAS pigs $(1.1 \pm 0.5)$. The expression of $I L 1 B, I L 8, I L 6$, IL10, TLR4 and TNF did not differ between the groups (data not shown), but positive correlations were observed between the distal small intestinal NEC score and the expression of $\operatorname{IL} 1 B(\rho=0.55$, $P<0.001)$ and $\operatorname{IL8}(\rho=0.50, P<0.001)$.

Bacterial abundance, location and fermentation products

FISH analyses of the distal small intestinal microbiota revealed no differences in bacterial location (pooled values, $2.0 \pm 0.1$ ) or abundance (pooled values, $2.0 \pm 0.2$ ) among the four groups. However, 
a positive correlation between the NEC score of the distal small intestine and the bacterial abundance score $(\rho=0.52, P<0.001)$ was observed.

In the stomach, the major OA were acetic, butyric, lactic and octanoic acid, while acetic, butyric, formic and lactic acid dominated in the colon (Figure 4a,b). In the stomach, the concentration of acetic and butyric acid was lower in FORM, relative to BC pigs, while octanoic acid was higher in FORM, COLOS and POW, compared with POWPAS pigs. In the colon, the concentration of acetic acid was lower in FORM, compared with POW and POWPAS pigs, and with a near-significant difference between COLOS and FORM pigs $(P=0.06)$. The concentration of lactic acid was lower across all BC pigs, compared with FORM pigs.

Migration of intestinal epithelial cells in vitro

Increased migration of IEC-6 cells was observed with increasing concentration of COLOS and POWPAS whey, resulting in a maximum increase in the migration at $10 \%$, relative to $0 \%$ whey. For POW whey, a maximum increase was observed at $1 \%$, relative to $0 \%$ POW whey, while the migration decreased at 5\% POW whey, and extensive cell lysis was observed at $10 \%$ (Figure 5a). Within concentrations, an increased migration was observed at $0.01 \%$ COLOS, relative to POW and POWPAS whey. Furthermore, the migration was increased for COLOS, compared with POWPAS at $0.1 \%$ and $1 \%$ whey. Finally, at $5 \%$ whey the migration was decreased for POW, compared with COLOS and PASPOW (Figure 5b).

\section{Characterisation of growth factors and proteins in colostrum products}

The IGF-I concentration was similar in COLOS, POW and POWPAS whey (pooled values, $1212 \pm$ $26 \mathrm{ng} / \mathrm{g}$ dry matter). The concentration of TGF- $\beta 1$ was higher in COLOS $(35.1 \pm 0.5 \mathrm{ng} / \mathrm{g}$ dry matter), compared with POW (18.7 $\pm 0.1 \mathrm{ng} / \mathrm{g})$ and POWPAS $(15.1 \pm 0.4 \mathrm{ng} / \mathrm{g})$, while the concentration of TGF- $\beta 2$ was lower in POWPAS $(166 \pm 5 \mathrm{ng} / \mathrm{g})$, compared with COLOS and POW (607 \pm 5 and $558 \pm 1 \mathrm{ng} / \mathrm{g}$, respectively). Non-centrifuged samples had a similar protein profile on 
the SDS-PAGE gel (Figure 6). Centrifugation resulted in removal of the majority of casein micelles ( $\sim 36 \mathrm{kDa}$, average diameter $120-180 \mathrm{~nm}(29))$ in all BC products, while a smaller population of residual casein micelles (average diameter $60 \mathrm{~nm}(30)$ ) remained. Qualitatively, protein aggregation was most pronounced in POWPAS, which was observed by a reduction in Ig (bands just below 250 $\mathrm{kDa}$ ) and proteins in the region $64-98 \mathrm{kDa}$, including lactoferrin and lactoperoxidase (both observed at $\sim 80 \mathrm{kDa}$ ). Still, all proteins of interest were detected also in POWPAS.

\section{Discussion}

Processing and sterilization of milk products reduce the content of milk bioactive factors, but the biological consequences of this are difficult to study in infants. We have previously shown that a raw $\mathrm{BC}$ product partially protects against NEC in preterm pigs $(6,18,31)$, and we now demonstrate that this protective effect remains after spray drying and pasteurisation of BC. Further studies are needed to show how processing conditions may affect the biological activity of BC products, especially since there was a tendency for the processed BCs in this study to be associated with slightly improved intestinal values, not only relative to formula, but also to untreated BC. While this would seem counter-intuitive, this is not impossible. The mild BC processing used in this study could potentially render some colostrum proteins more digestible for an immature gut, while

retaining the major part of the beneficial bioactivity. The results from the in vivo study were supported by the in vitro study where increasing concentration of $\mathrm{BC}$ whey increased migration of intestinal epithelial cells, as a measure of wound healing properties. In this case, the best migration effect was seen with COLOS whey, and this ability of BC to stimulate cell migration and healing of epithelial wounds might be particularly important for the sensitive epithelium of preterm newborns. In the in vitro study, the majority of parameters of intestinal structure and functions were improved to a similar extent across the three groups of BC-fed pigs, relative to pigs fed formula. A smaller intestinal circumference and increased villus height and distal small intestinal enzyme activity in the $\mathrm{BC}$ pigs indicate increased protection against loss of muscular tone, mucosal atrophy and brush- 
border enzyme dysfunction. Hexose absorptive function, measured by plasma galactose levels, decreased dramatically during the initial $6 \mathrm{~h}$ of formula feeding in all pigs, while it remains high when BC is fed immediately after TPN (6). However, the mucosa regained its hexose absorptive capacity when the pigs subsequently were fed BC products, while the value remained low after continued formula feeding. Contrary to our earlier studies, all pigs in this study were fed a few boluses of formula after the TPN period and this initiates an intestinal inflammatory response, as shown previously (32). It was therefore not surprising that we observed signs of inflammation in all three BC groups and higher NEC score/severity than in preterm pigs transitioned to colostrum products from birth or immediately after the TPN period $(6,18,31)$. Coupled with these previous observations, our results indicate that $\mathrm{BC}$ may work both as a preventive diet and a therapeutic diet to combat gut inflammatory processes in the immature intestine.

Colostrum feeding resulted in decreased IL-1 $\beta$ and IL-8 levels in the distal small intestinal tissue and thereby reversed the initial pro-inflammatory state induced by combined TPN and initial formula feeding. Sow's colostrum also down-regulate such inflammatory responses, as indicated by decreased IL-1 $\beta$ (33), confirming that colostrum obtained from different species may exert similar effects on the immature intestine, at least in pigs. The BC-protective effects were less clear when measuring cytokine gene expression levels, compared with protein levels, at least for IL-1 $\beta$ and IL8. A lack of consistency between cytokine mRNA and protein levels may be explained by a difference in the onset of the expression of a certain gene and the production and secretion of the protein that follows (34). The correlation between the expression of IL1B and the distal small intestinal NEC score suggests a close relationship between the expression of this inflammatory mediator and the degree of intestinal inflammation, more than a relation with the type of diet. This is supported by a recent study that showed only four genes (DEFB1, CXCL10, IL1RN, and ALPI) of 48 genes to be differentially regulated between BC and FORM preterm pigs (35). Similarly, the mucosal bacterial abundance in the distal intestine correlated positively with the NEC score in that region, but not with diet. This indicates that the density of the mucosal microbiota is not very diet- 
independent but more related to the progression of inflammation and tissue lesions $(9,36)$. On the other hand, excessive fermentation in the colon lumen, especially indicated by increased lactate levels, was more prevalent in FORM pigs and this may play a separate role for increased inflammation in this group.

Interestingly, no differences in protein aggregation were observed between the COLOS and POW products indicating that the type of spray drying used in this study did not markedly damage the milk proteins. In contrast, pasteurisation resulted in a higher degree of protein aggregation and it also reduced the concentration of important milk bioactives, such as TGF- $\beta 2$. Both spray drying and pasteurisation reduced the concentration of TGF- $\beta 1$, while IGF-I was not affected by neither of the procedures. This suggests that a significant number of milk proteins remains unaffected by processing and may contribute to beneficial biological effects of processed $\mathrm{BC}$ on the immature intestine. The irradiation dose used in this study did not appear to lead to significant denaturation of $\mathrm{BC}$ proteins, which was indicated in a study comparing irradiated $\mathrm{BC}$ from this study and nonirradiated BC from the same pool of colostrum (unpublished results).

We conclude that spray dried and pasteurised $\mathrm{BC}$ improves gut function and $\mathrm{NEC}$ prevention in preterm pigs in the immediate postnatal period. Consequently, BC products may serve as valuable alternatives to infant formula and banked human donor milk during the first critical days after preterm birth, if mother's milk is not available. Potentially, such products may also serve to fortify mother's milk or human donor milk with highly digestible and bioactive proteins. Studies on the efficacy of BC products to promote growth, food tolerance and NEC protection in the first few weeks of life for preterm infants are warranted.

\section{Acknowledgements}

We wish to thank Mette Schmidt at Department of Large Animal Sciences/Veterinary Reproduction and Obstetrics, University of Copenhagen for assistance with animal procedures, Bent B. Jensen at Department of Animal Science, Aarhus University, for analysis of organic acid concentrations, and 
Annette K. Nielsen and Kasper B. Poulsen, Department of Animal Science, Aarhus University, for skilled technical assistance.

\section{Reference List}

1. Chatterton DE, Nguyen DN, Bering SB, et al. Anti-inflammatory mechanisms of bioactive milk proteins in the intestine of newborns. Int J Biochem Cell Biol 2013;45:1730-47.

2. Korhonen H, Pihlanto A. Technological options for the production of health-promoting proteins and peptides derived from milk and colostrum. Curr Pharm Des 2007;13:829-43.

3. Playford RJ, MacDonald CE, Johnson WS. Colostrum and milk-derived peptide growth factors for the treatment of gastrointestinal disorders. Am J Clin Nutr 2000;72:5-14.

4. Sangild PT. Gut responses to enteral nutrition in preterm infants and animals. Exp Biol Med 2006;231:1695-1711.

5. Stelwagen K, Carpenter E, Haigh B, et al. Immune components of bovine colostrum and milk. J Anim Sci 2009;87:3-9.

6. Støy AC, Heegaard PMH, Thymann T, et al. Bovine colostrum improves intestinal function following formula-induced gut inflammation in preterm pigs. Clin Nutr 2014;33:322-9.

7. Li Y, Jensen ML, Chatterton DE, et al. Raw bovine milk improves gut responses to feeding relative to infant formula in preterm piglets. Am J Physiol Gastrointest Liver Physiol 2014;306:G81-90.

8. Jensen ML, Sangild PT, Lykke M, et al. Similar efficacy of human banked milk and bovine colostrum to decrease incidence of necrotizing enterocolitis in preterm piglets. Am J Physiol Regul Integr Comp Physiol 2013;305:R4-12.

9. Cilieborg MS, Boye M, Thymann T,et al. Diet-dependent effects of minimal enteral nutrition on intestinal function and necrotizing enterocolitis in preterm pigs. JPEN J Parenter Enteral Nutr 2011;35:32-42. 
10. Shen RL, Thymann T, Ostergaard MV, et al. Early gradual feeding with bovine colostrum improves gut function and NEC resistance relative to infant formula in preterm pigs. Am $\mathrm{J}$ Physiol Gastrointest Liver Physiol 2015;309:G310-23.

11. Meinzen-Derr J, Poindexter B, Wrage L, et al. Role of human milk in extremely low birth weight infants' risk of necrotizing enterocolitis or death. J Perinatol 2008;29:57-62.

12. Sisk PM, Lovelady CA, Dillard RG, et al. Early human milk feeding is associated with a lower risk of necrotizing enterocolitis in very low birth weight infants. J Perinatol 2007;27:428-33.

13. Sullivan S, Schanler RJ, Kim JH, et al. An exclusively human milk-based diet is associated with a lower rate of necrotizing enterocolitis than a diet of human milk and bovine milk-based products. J Pediatr 2010;156:562-7.

14. Schanler RJ, Lau C, Hurst NM, et al. Randomized trial of donor human milk versus preterm formula as substitutes for mothers' own milk in the feeding of extremely premature infants. Pediatrics 2005; 116:400-6.

15. Aunsholt L, Jeppesen PB, Lund P, et al. Bovine colostrum to children with short bowel syndrome: A randomized, double-blind, crossover pilot study. JPEN J Parenter Enteral Nutr 2012;38:99-106.

16. Li Y, Petersen SM, Ye X, et al. Bovine colostrum as nutrition for preterm infants in the first days of life: A pilot feasibility study (Precolos-Neomune). 48th annual meeting of the ESPGHAN.Volume 2015:158.

17. Li Y, Østergaard MV, Jiang P, et al. Whey protein processing influences formula-induced gut maturation in preterm pigs. J Nutr 2013;143:1934-42.

18. Bjornvad CR, Thymann T, Deutz NE, et al. Enteral feeding induces diet-dependent mucosal dysfunction, bacterial proliferation, and necrotizing enterocolitis in preterm pigs on parenteral nutrition. Am J Physiol Gastrointest Liver Physiol 2008;295:G1092-1103. 
19. Puiman PJ, Jensen M, Stoll B, et al. Intestinal threonine utilization for protein and mucin synthesis is decreased in formula-fed preterm pigs. J Nutr 2011;141:1306-11.

20. Siggers RH, Thymann T, Jensen BB, et al. Elective cesarean delivery affects gut maturation and delays microbial colonization but does not increase necrotizing enterocolitis in preterm pigs. Am J Physiol Regul Integr Comp Physiol 2008;294:R929-38.

21. Thymann T, Møller HK, Stoll B, et al. Carbohydrate maldigestion induces necrotizing enterocolitis in preterm pigs. Am J Physiol Gastrointest Liver Physiol 2009;297:G1115-25.

22. Sangild PT, Sjostrom H, Noren O, et al. The prenatal development and glucocorticoid control of brush-border hydrolases in the pig small intestine. Pediatr Res 1995;37:207-12.

23. Thymann T, Burrin DG, Tappenden KA, et al. Formula-feeding reduces lactose digestive capacity in neonatal pigs. Br J Nutr 2006;95:1075-81.

24. Bjerre M, Hansen TK, Flyvbjerg A, et al. Simultaneous detection of porcine cytokines by multiplex analysis: development of magnetic bioplex assay. Vet Immunol Immunopathol 2009;130:53-8.

25. Mølbak L, Thomsen LE, Jensen TK, et al. Increased amount of Bifidobacterium thermacidophilum and Megasphaera elsdenii in the colonic microbiota of pigs fed a swine dysentery preventive diet containing chicory roots and sweet lupine. J Appl Microbiol 2007;103:1853-67.

26. Canibe N, Hojberg O, Badsberg JH, et al. Effect of feeding fermented liquid feed and fermented grain on gastrointestinal ecology and growth performance in piglets. J Anim Sci 2007;85:2959-71.

27. Purup S, Nielsen TS. Cell-based models to test the effects of milk-derived bioactives. Animal $2012 ; 6: 423-32$.

28. Purup S, Vestergaard M, Pedersen LO, et al. Biological activity of bovine milk on proliferation of human intestinal cells. J Dairy Res 2007;74:58-65. 
29. Farrell J, Pessen H, Brown EM, et al. Structural insights into the bovine casein micelle: Small angle X-ray scattering studies and correlations with spectroscopy. J Dairy Sci 1990;73:35923601.

30. Ono T, Furuyama T, Odagiri S. Dissociation of large and small bovine casein micelles by dialysis. Agric Biol Chem 1981;45:511-2.

31. Møller HK, Thymann T, Fink LN, et al. Bovine colostrum is superior to enriched formulas in stimulating intestinal function and necrotising enterocolitis resistance in preterm pigs. Br J Nutr 2011;105:44-53. 32

32. Siggers JL, Sangild PT, Jensen TK, et al. Transition from parenteral to enteral nutrition induces immediate diet-dependent gut histological and immunological responses in preterm neonates. Am J Physiol Gastrointest Liver Physiol 2011;301:G435-45.34

33. Van Haver ER, Sangild PT, Oste M, et al. Diet-dependent mucosal colonization and interleukin-1 beta responses in preterm pigs susceptible to necrotizing enterocolitis. J Pediatr Gastroenterol Nutr 2009;49:90-8.

34. Sørensen NS, Skovgaard K, Heegaard PM. Porcine blood mononuclear cell cytokine responses to PAMP molecules: comparison of mRNA and protein production. Vet Immunol Immunopathol 2011;139:296-302.

35. Støy ACF, Heegaard PMH, Sangild PT, Østergaard MV, Skovgaard K. Gene expression analysis of the IPEC-J2 cell line: A simple model for the inflammation-sensitive preterm intestine. ISRN Genomics 2013; Doi:10.1155/2013/980651.

36. Støy ACF, Mølbak L, Delegue CL, Thymann T, Sangild PT, Heegaard PM, Manurung S, Skovgaard K. Necrotizing enterocolitis in preterm pigs is associated with increased density of intestinal mucosa-associated bacteria including Clostridium perfringens. Neonatology 2015;108:188-95. 


\section{Figure legends}

Figure 1: Mean NEC score (a), NEC incidence (b), life span (c), distal small intestinal villus height (d), small intestinal circumference (e), activity of brush-border enzymes (pool across small intestinal regions): aminopeptidase A (f), aminopeptidase N (g), dipeptidylpeptidase IV (h), lactase (i), and maltase (j), in preterm pigs fed formula (FORM, white bars), bovine colostrum (COLOS, light grey bars), reconstituted spray dried bovine colostrum (POW, dark grey bars) or reconstituted, pasteurised and spray dried bovine colostrum (POWPAS, black bars). Data are presented as means + SEM, and means not sharing the same superscript letters are significantly different $(P<0.05)$.
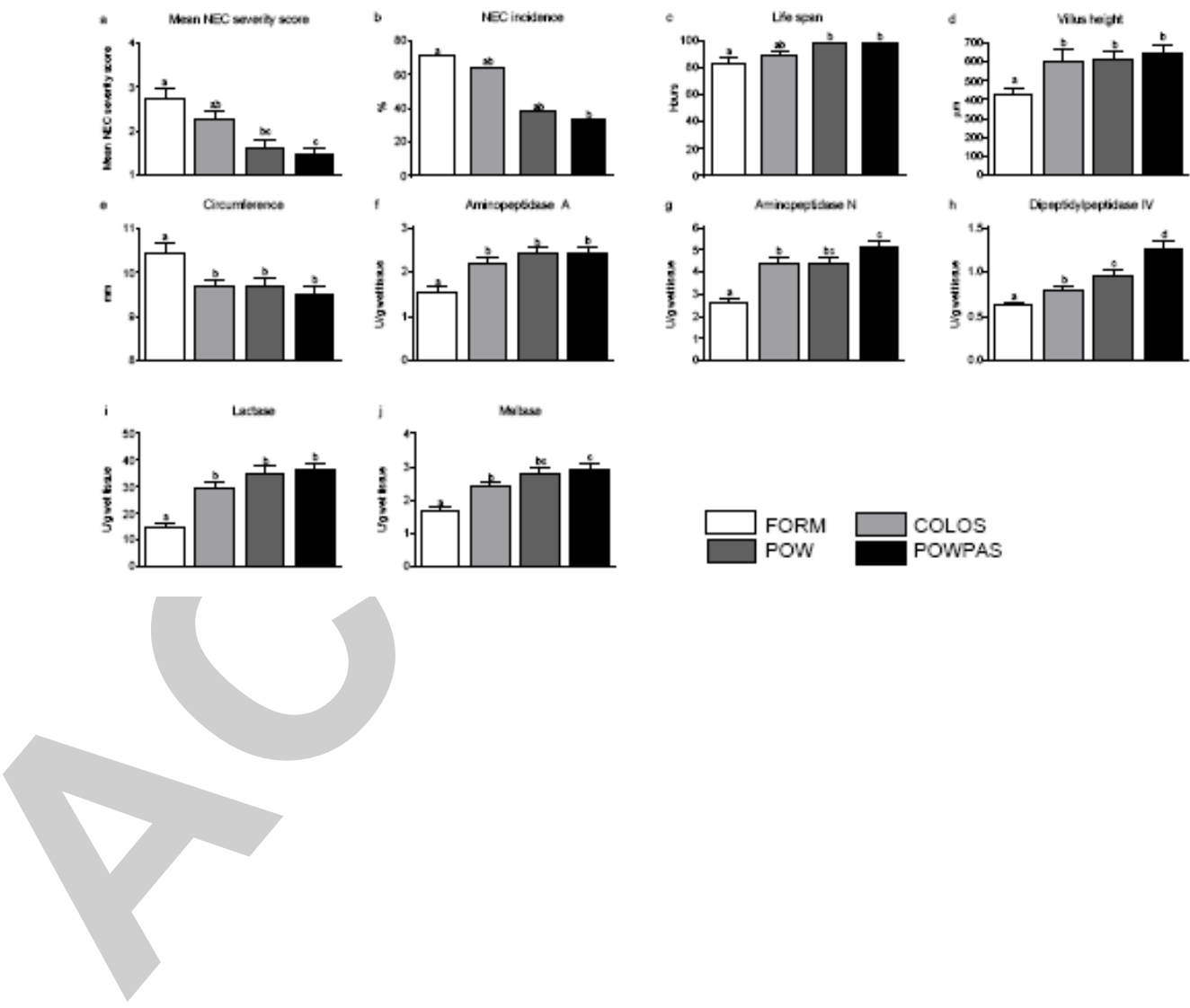
Figure 2: Intestinal absorption capacity measured as plasma levels of galactose after an oral bolus of galactose given before enteral feeding $(0 \mathrm{~h})$, after $6 \mathrm{~h}$ of formula feeding $(6 \mathrm{~h})$, and after $24 \mathrm{~h}$ of enteral feeding with the respective treatment diets $(30 \mathrm{~h})$ in preterm pigs fed formula (FORM, white bars), bovine colostrum (COLOS, light grey bars), reconstituted spray dried bovine colostrum (POW, dark grey bars) or reconstituted, pasteurised and spray dried bovine colostrum (POWPAS, black bars). The data was analysed within each time point and presented as means + SEM. Means not sharing the same superscript letters within each time point differ significantly $(P<0.05)$.

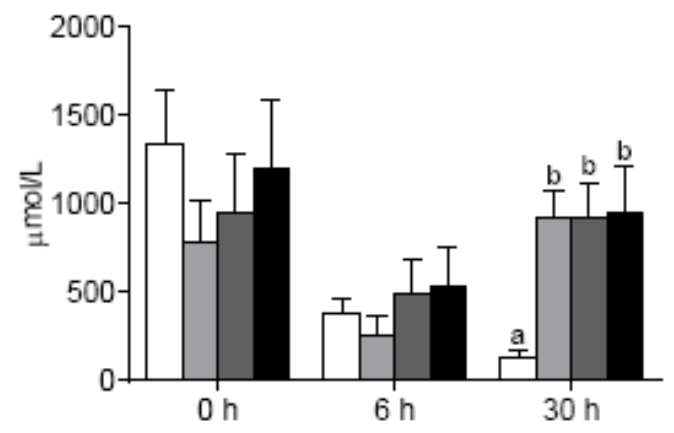


Figure 3: Distal small intestinal concentrations for IL-1 $\beta$ (a) and IL-8 (b) in preterm pigs fed formula (FORM, white bars), bovine colostrum (COLOS, light grey bars), reconstituted spray dried bovine colostrum (POW, dark grey bars) or reconstituted, pasteurised and spray dried bovine colostrum (POWPAS, black bars). Data are presented as means + SEM, and means not sharing the same superscript letters are significantly different $(P<0.05)$.

a

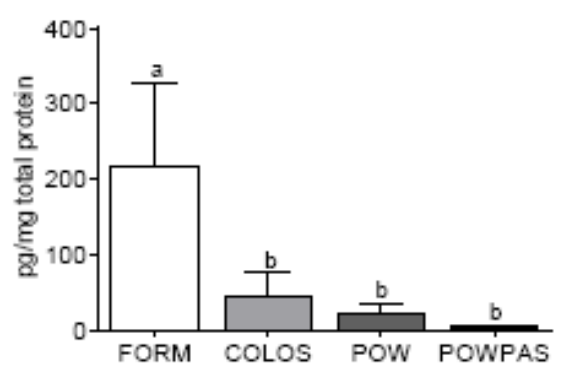

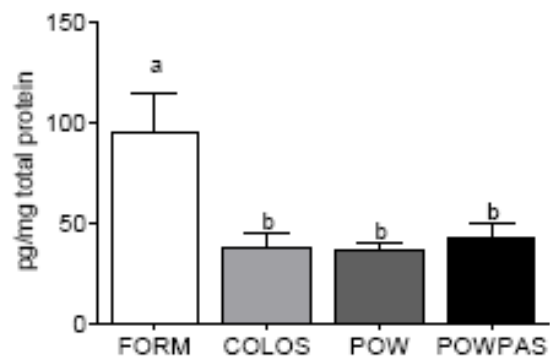


Figure 4: Total concentration and the concentration of the dominating OA in stomach (a) and colon (b) contents of preterm pigs fed formula (FORM, white bars), bovine colostrum (COLOS, light grey bars), reconstituted spray dried bovine colostrum (POW, dark grey bars) or reconstituted, pasteurised and spray dried bovine colostrum (POWPAS, black bars). Different superscript letters indicate significant differences $(P<0.05)$.
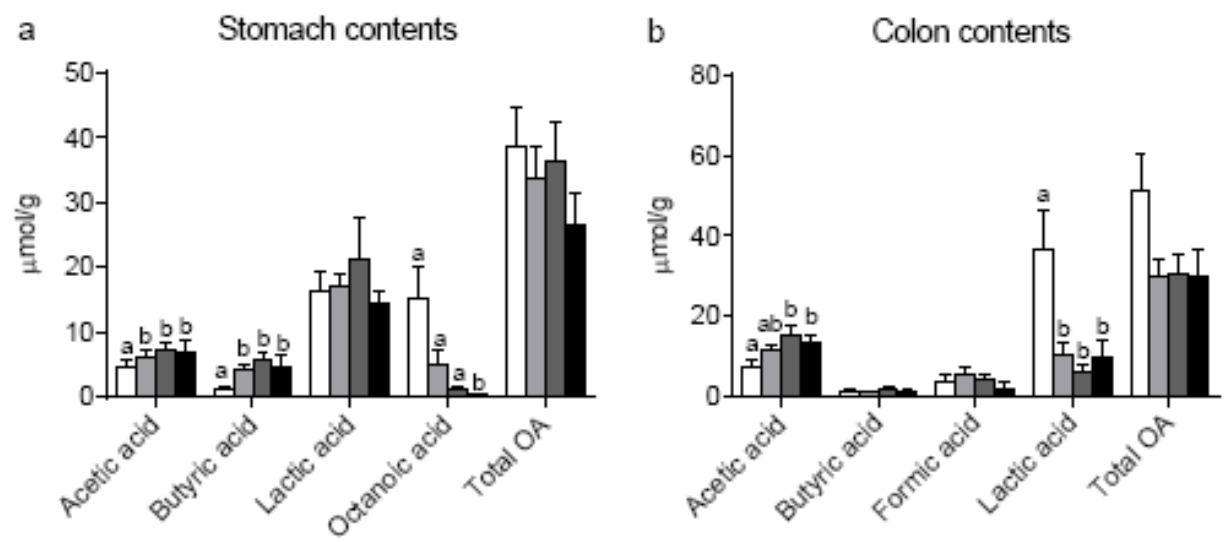
Figure 5: Migration of IEC-6 cells, as an in vitro model of the wound healing capacity of intestinal epithelial cells. Increasing amounts of whey (0-10\%) from bovine colostrum (COLOS), reconstituted spray dried bovine colostrum (POW) and reconstituted, pasteurised and spray dried bovine colostrum (POWPAS), where the relative migration is calculated relative to $0 \%$ whey within each BC product (a). Effect of bovine colostrum (COLOS, light grey bars), reconstituted spray dried bovine colostrum (POW, dark grey bars) or reconstituted, pasteurised and spray dried bovine colostrum (POWPAS, black bars) on the migration within each concentration, where the relative migration is calculated relative to COLOS within each concentration (b). Significant differences between different concentrations of each product (a) or with concentrations (b) are indicated by different letters $(P<0.05)$.

a

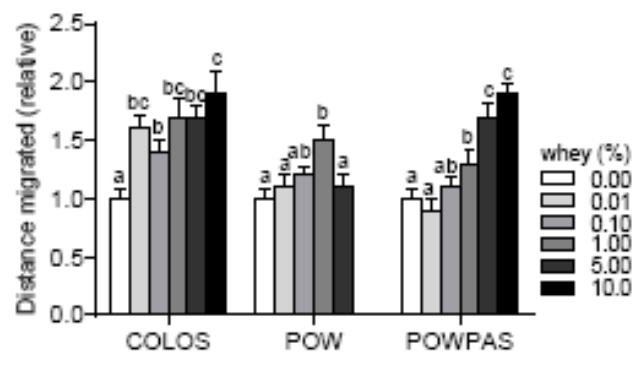

b

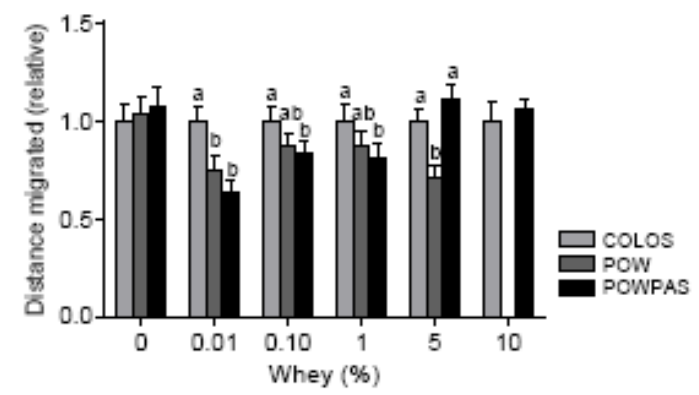

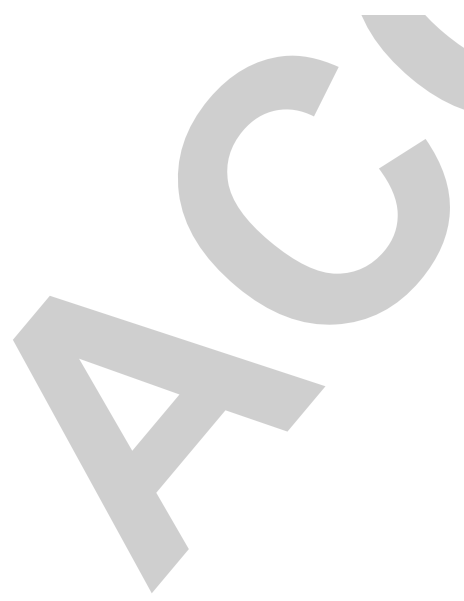


Figure 6: Effects of spray drying and pasteurisation on protein aggregation in colostrum. Untreated total colostrum proteins: lane 1, bovine colostrum; lane 2, reconstituted spray dried bovine colostrum; lane 3, reconstituted, pasteurised and spray dried bovine colostrum; and proteins remaining in the supernatant following removal of aggregated proteins by centrifugation (15 min; 13,000g): lane 4, bovine colostrum; lane 5, reconstituted spray dried bovine colostrum; lane 6 reconstituted, pasteurised and spray dried bovine colostrum. M: Molecular weight marker. Immunoglobulin band indicated by the black arrow.

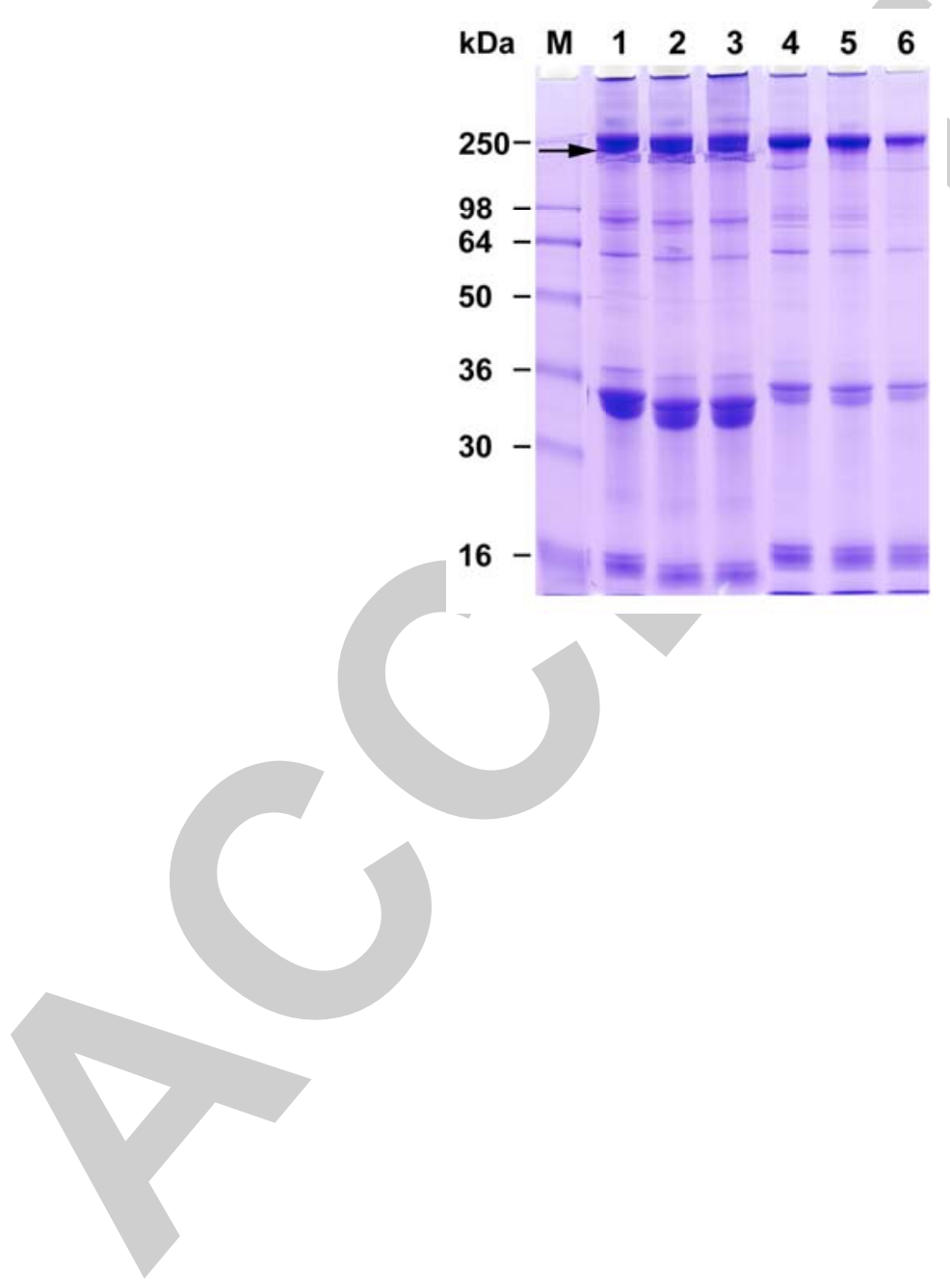

